\title{
INFÂNCIA YUDJÁ E A EDUCAÇÃO EM UM MUNDO VIVO: PENSAMENTOS EM TORNO DO FILME WAAPA*
}

Minhas primeiras letras foram o céu e o chão leio religiosamente na carne das plantas nos versos da água na pele do Sol nos resíduos do vento leio intuitivamente antes de me existir

(Joshua , 2026)

Este texto faz parte de alguns movimentos que tenho realizado em pesquisas $^{1}$ e na formação de professoras(es), no sentido de criar encontros férteis entre a Educação, as Artes e as cosmovisões dos povos indígenas brasileiros (WUNDER, 2017). Tenho realizado pesquisas acerca de produções literárias e audiovisuais (fotografia, cinema e artes visuais) de artistas indígenas e também de artistas não indígenas que criam obras em colaboração com os povos originários. Interessam-me os caminhos de pensamento e criação com os regimes conceituais e visualidades ameríndias que estas produções artísticas oferecem. Interessa-me pensar com imagens, com a arte e com seus processos criativos que se dão no encontro na diferença.

Que outras perspectivas de educação, de humanidade, de mundo esses povos estão oferecendo com suas imagens e narrativas? Quais os conceitos que permeiam a educação de cada povo indígena? Como seria repensar nossos conceitos a partir de um olhar atento aos seus modos de educar? Como a educação das crianças pode ser pensada a partir desses outros modos de relação com o mundo? Encontrar com

\footnotetext{
*DOI - 10.29388/978-65-86678-02-4-0-f.73-92

${ }^{1}$ Pesquisadora do Laboratório de Estudos Audiovisuais, OLHO da Faculdade de Educação da Universidade Estadual de Campinas.
} 
os regimes conceituais indígenas e produzir uma obra sobre as lógicas vão no sentido do que alguns teóricos e teóricas têm nos convidado a fazer. Os pensamentos podem ser imaginados como superfícies que, no encontro com outros, podem dobrar-se. Esta é a ideia de obra do filósofo Gilles Deleuze: uma força de instabilidade em que o fora se torna dentro e o dentro de torna fora. Nessas curvas, as diferenças se encontram. E é desse precioso entrelugar que busco escrever, desde o espaço criativo que se faz no encontro entre as lógicas do pensamento ocidental, das quais compartilho como professora e pesquisadora não indígena, e as lógicas de pensamento dos distintos povos. Para o antropólogo Eduardo Viveiros de Castro (2008), o pensamento dos povos originários tem validade e sentido não apenas para suas sociedades, mas também para nos forçar a rever os conceitos construídos nas diversas áreas de conhecimento. Como o autor propõe, poderíamos fazer cada vez mais uma "antropologia simétrica", ou seja, "antropologizar o 'centro' e não apenas a 'periferia' de nossa cultura. O centro da nossa cultura é o estado constitucional, é a ciência, é o cristianismo" (VIVEIROS DE CASTRO, 2008, p.46). Para a educação, seria o convite a um movimento inquietante de olhar para as nossas teorias e práticas a partir de outras perspectivas de mundo.

Acompanhada de perguntas, ofereço aqui algumas palavras que brotam do encontro com o filme Waapa (2017), curta-metragem que traz alguns dos princípios da educação das crianças do povo indígena Yudjá. Também conhecidos como Jurunas, nome dado pelos povos indígenas vizinhos, os Yudjá atualmente reivindicam este outro nome, sua autonomeação que significa "os donos do rio". Eles sempre viveram ao longo do rio Xingu; nos últimos quatro séculos, migraram do norte do Pará em direção ao sul e hoje vivem, em sua maioria, no território do Parque Indígena do Xingu, no Mato Grosso. Atualmente são uma população de aproximadamente quinhentas pessoas, distribuídas em sete aldeias, que, segundo a linguista Cristina Fargetti, "são sobreviventes de um grande decréscimo populacional - estima-se que na década de 1960 não chegassem a cinquenta pessoas" (FARGETTI, 2017, p.23). No encarte do CD "Fala de bicho, fala de gente", realizado 
pela cantora e pesquisadora de musicalidades indígenas Marlui Miranda, juntamente com os Yudjá, Yabaiwá Juruna, professor e pensador yudjá, escreve a respeito da história de seu povo:

Os Juruna, como também são chamados os Yudjá, formavam um dos povos mais importantes do Rio Xingu, porque antigamente a nossa população era muito grande. Nossos antepassados eram os antigos habitantes das ilhas peninsulares do baixo e meio curso do Rio Xingu, um dos maiores da Amazônia. Iya Xipaa na nossa língua significa "rio principal. Yudjá na nossa língua significa "dono do rio", porque na nossa história os nossos ancestrais libertaram o rio que antes ficava preso dentro de um tipo de geleira ou caixa de gelo. A nossa história está ligada a fundação da cidade de Belém. Em meados do século XVIII, o abandono de toda região do baixo Xingu pelos indígenas foi resultado mais evidente dos primeiros cem anos de uma história marcada pelo aprisionamento, escravização, guerra e predação (MIRANDA, 2014, s/p).

Os Yudjá são um dos vários povos indígenas amazônicos que sobreviveram ao genocídio, às invasões de terra, às doenças do contato, à escravização, à evangelização forçada, e que se revitalizaram após séculos de fuga. Falam hoje sua língua originária e sustentam na vida cotidiana suas narrativas, seus cantos, seus rituais, suas artes materiais, suas práticas de agricultura, de cura e de educação que se dão numa relação íntima com o rio. Exímios canoeiros, os Yudjá são os "donos do rio", vieram do rio, salvaram-se pelo rio, vivem, aprendem e ensinam com suas águas e com todos os seres que fazem parte de sua "malha de vida". (INGOLD, 2017)

O filme Waapa, lançado em 2017, foi realizado pelos diretores Renata Meirelles, David Reeks e Paula Mendonça, juntamente com Yabaiwá Juruna, na Aldeia Tuba Tuba, no Parque Nacional do Xingu - MT. Pode-se pensar no filme como uma ritualística de encontro entre pessoas diferentes conectadas pelas crianças e pelos modos diversos de educar. Yabaiwá é professor da Escola Kamadu, da aldeia Tuba 
Tuba e também narrador e autor do argumento do curta-metragem. Os documentaristas David Reeks e Renata Meirelles desenvolvem juntos pesquisas e filmes sobre as culturas tradicionais das infâncias no Brasil, e coordenam o Programa Territórios do Brincar, que realiza intercâmbio de saberes, registro e difusão da cultura infantil. ${ }^{2}$ Paula Mendonça foi, durante dez anos, assessora pedagógica da Escola $\mathrm{Ka}$ madu, pelo Instituto Socioambiental. Durante esses anos, passou longos períodos nas aldeias yudjá e participou do processo de formação de professores, da produção de material didático e da elaboração de Projetos Político-Pedagógicos de escolas indígenas. A partir desses trabalhos, realizou a pesquisa de Mestrado intitulada Corpo preparado, alma protegida: jeitos de cuidar e modos de aprender no crescimento da criança yudjá, pela Faculdade de Educação da Universidade Estadual de São Paulo (MENDONÇA, 2007). A pesquisa investiga os modos de educação das crianças yudjá, bem como as possibilidades e os limites do diálogo intercultural entre essas práticas educativas e a educação escolar indígena.

Da aliança entre educadores, artistas, pesquisadores, indígenas e não indígenas nasce a obra Waapa. Em vinte minutos, o filme oferece cenas de brincadeiras que são também práticas de aprendizagem, cura e preparo do corpo das crianças para os desafios da vida. São as palavras de Yabaiwá que traçam as relações dessas práticas com a cosmovisão dos Yudjá e que enredam as imagens da poética câmera do cinegrafista David Reeks. Paula Mendonça, em sua dissertação de Mestrado, destaca diversas ações educativas dos yudjá:

É possível elencar um conjunto de ações intencionais implicadas na educação das crianças: saber ouvir e compreender, observar e memorizar, ter o corpo liso para as doenças escorregarem, saber falar bem, prevenir-se das alergias alimentares, além da força, equilíbrio e agilidade, assim como pontaria e velocidade. Por um lado trabalha-se os atributos físicos e por outro a rede espiritual que confere proteção às pessoas que estão em perigo.

\footnotetext{
${ }^{2}$ Site do Programa Territórios do Brincar: territórios do brincar https://territoriodobrincar.com.br/
} 
Também faz parte o uso de remédios que favorecem e aguçam a percepção, assim como na ideia de Ingold a educação da atenção. Além disso são usados brinquedos que têm como finalidade, além do divertimento, oferecer a proteção necessária para que a criança possa ter boa saúde. Vimos que o brincar é uma forma de perceber que a criança está com boa saúde, porque denota seu vínculo e relações com as coisas e pessoas desse mundo (MENDONÇA, 2017, p. 153).

Waapa foca especialmente este último conjunto de ações: as brincadeiras, que fortalecem o vínculo e as relações das crianças com o mundo. Com elas, o corpo da criança entra em relação de aprendizagem com diversos outros corpos não humanos. Nessa outra forma de aprendizagem, a perspectiva das(os) mulheres/homens parece não ser central, nele há aberturas às perspectivas, intenções e forças de todos os outros seres.

Busco neste exercício de pensamento com as imagens, palavras e sons do filme, conversar com algumas ideias do antropólogo inglês Tim Ingold, em seu livro Estar vivo: ensaios sobre movimento, conhecimento e descrição (2017). Os ensaios desse livro vão no sentido de "inserir o ser humano e o devir na continuidade do mundo da vida" (INGOLD, 2017, p. 26). Ingold instaura um pensamento no qual as/os humanas/os estão imersos nas linhas vitais, seguindo os fluxos que se dão sempre nas relações e em movimentos de transformação. Defende um modo de habitar, relacionar-se, conhecer e pensar o mundo a partir de uma conversação com as "vozes" outras que compõem o chão em que pisamos:

Por que reconhecemos apenas nossas fontes textuais, mas não o chão que pisamos, os céus em constante mudança, montanhas e rios, rochas e árvores, as casas nas quais habitamos e as ferramentas que usamos, para não mencionar os inúmeros companheiros, tanto animais não-humanos como os outros seres humanos, com os quais e com quem compartilhamos nossas vi- 
das? Eles estão constantemente nos inspirando, nos desafiando, nos dizendo coisas (INGOLD, 2017, p. 12).

Ingold, bastante impregnado pelo pensamento de povos originários, defende um movimento vital e expandido de aprendizagem com o mundo, no qual as dimensões conceituais que cindem natureza e cultura são deslocadas. As fronteiras entre mundo humano e mundo natural, construídas secularmente pelo pensamento moderno e pela divisão disciplinar do conhecimento, ganham linhas de fuga. Linhas que criam um emaranhado vital de relações e abrem horizontes para imaginar outras subjetividades e outras formas de educar em uma relação intensiva com a vida.

Figura 1 frame 00:38 do filme Waapa

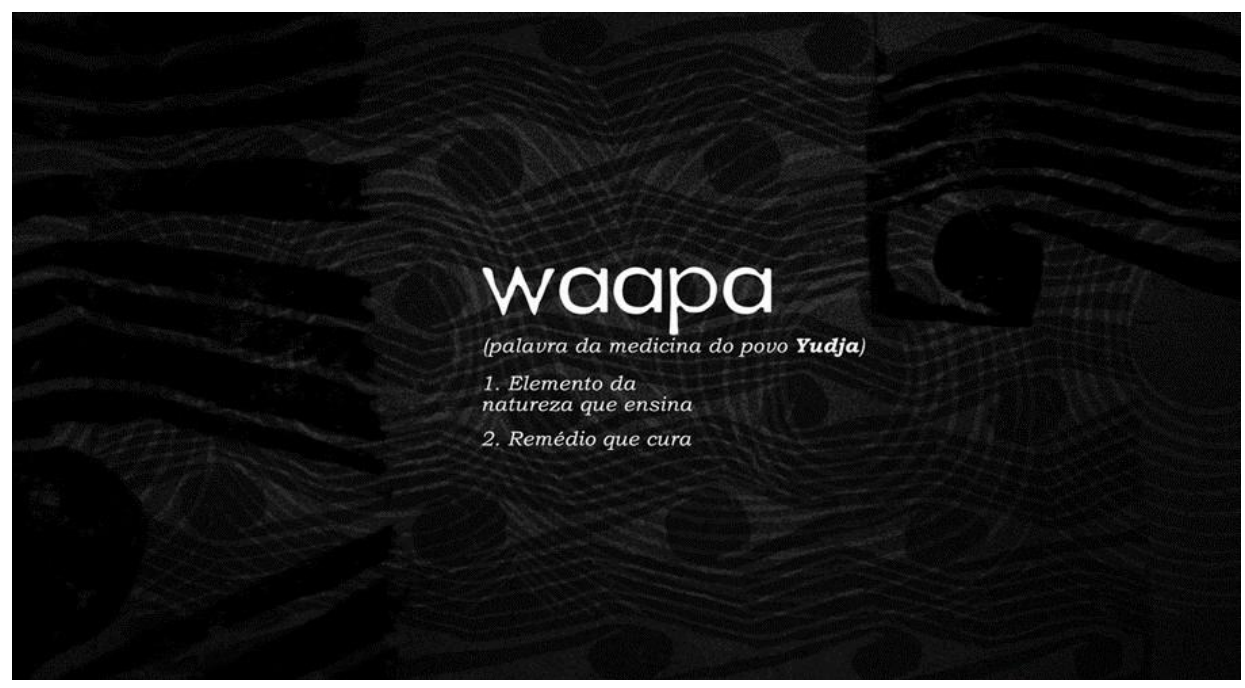

Nos primeiros segundos do filme, os grafismos dos yudjá misturam-se com as palavras, entrando-se em contato com um outro regime visual e conceitual. Chega o convite para entrar na forma singular de educação das crianças yudjá: waapa (palavra da medicina do povo Yudja). 1. Elemento da natureza que ensina. 2. Remédio que cura. Waapa é um conceito que desestabiliza a indistinção entre cura e 
educação, entre remédio e conhecimento. Desestabiliza a pensar a Educação a partir de um elemento natural, o gesto de educar descentrado das(os) humanas/os e potencializando a ação dos seres e das coisas numa prática educativa. É em torno deste conceito waapa que as palavras do narrador Yabaiwá e as imagens e os sons vão se desdobrar no filme.

Figura 2 frame 01:12 do filme Waapa

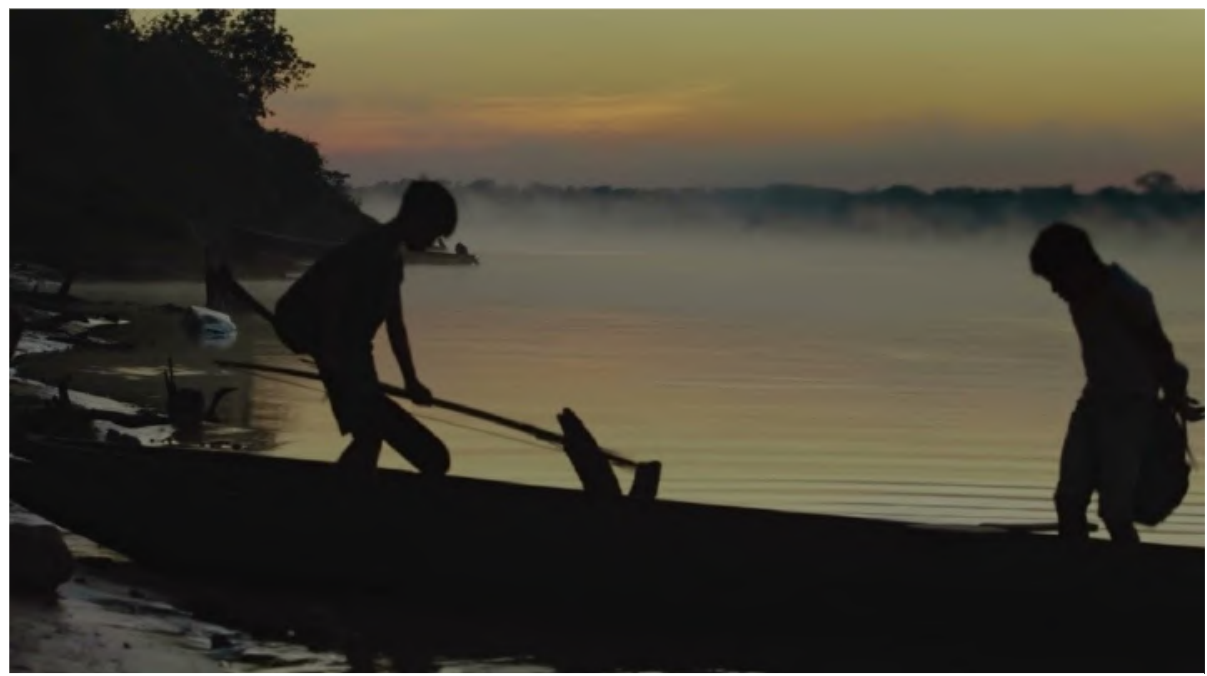

Som de sapos na floresta. Amanhecer. O rio espelha o céu, a floresta e a névoa. Dois meninos entram em uma canoa. "Estamos indo". Diz um deles. "Para onde a gente vai?". Ficamos sem a resposta e o filme segue o curso da viagem das crianças pelo rio. A viagem conecta-se a uma narrativa de criação: "Quando o deus libertou o rio, o deus era os Yudjá. Yudjá é um nome que vem de muito tempo, significa 'o povo do rio' ou 'o dono do rio'. É por isso que hoje a gente não consegue ficar longe do rio. Para mim ser Yudjá é fazer parte de tudo, de tudo que Yudjá faz. E é por isso que a gente está ensinando isso para os meninos, essa cultura, vamos dizer assim”. As primeiras imagens e palavras do filme levam às águas que alimentam e dão sentido ao modo de ser yudjá: suas histórias de princípio do mundo, em que um deus humano liberta o rio e gera a vida. A vida é resultado de uma 
criação conjunta, fruto de uma relação entre um ser espiritual, humanas/os e seres outros, para os Yudjá, uma criação entre Selaã, as/os humanas/os e o rio. Cada povo tem sua narrativa de princípio do mundo. As histórias de criação dos trezentos e quatro povos indígenas brasileiros expressam suas formas outras de habitar o mundo, ou melhor, expressam os outros mundos que os diversos povos indígenas criam ao habitá-lo. No livro Antes o mundo não existia: mitologia dos antigos Desana-Kehíripõrã, de autoria dos desana Firmiano Lana e Luiz Gomes Lana (1995), Yebá Buró é a avó do mundo, a primeira mulher que aparece por si mesma desde a escuridão:

No princípio o mundo não existia. As trevas cobriam tudo. Enquanto não havia nada, apareceu uma mulher por si mesma. Isso aconteceu no meio das trevas. Ela apareceu sustentando-se sobre o seu banco de quartzo branco. Enquanto estava aparecendo, ela cobriu-se com seus enfeites e fez como um quarto (LANA \& LANA, 1995, p. 19).

Na narrativa de criação do povo Desana, que vive na região amazônica do Alto Rio Negro, a vida se faz na relação entre o escuro, uma mulher e um conjunto de coisas. A mulher aparece acompanhada por um banco de cristal, uma cuia de farinha de tapioca, um suporte de cuia, folhas de ipadu, um cigarro e uma forquilha para segurá-lo. Junto com estas coisas, a Yebá Buró, também chamada de a "Não criada", sentada em seu banco de quartzo, fuma o cigarro, come o ipadu e pensa sobre o futuro do mundo, que ela chama de "maloca do universo" (LANA \&LANA, 1995, p. 19). A ideia de que a vida se dá a partir de um fluxo criativo entre seres/coisas é uma imagem que se distingue da lógica judaico-cristão, na qual a vida é resultado da ação externa de um único criador com características humanas e masculinas. E também se distingue do pensamento moderno, acentuado pela lógica capitalista, no qual a vida está sob o domínio de uma humanidade que se vê como gerenciadora de um mundo todo objetivado. Os seres/coisas não humanos como parte da criação do mundo são subjetividades outras e não recursos à disposição das(os) huma- 
nas(os). Nessa outra lógica ontogênica, os seres/coisas do cosmos têm perspectivas e se comunicam entre si e com a humanidade, que faz parte dos movimentos da vida de forma menos centralizada e hierárquica.

Uma folha de palmeira carrega um menino pelo chão da aldeia, a mandioca marca o ritmo da aldeia: colher, ralar, pilar, secar, torrar, cozinhar, comer. A água banha o corpo das crianças, o fogo aquece, a fumaça se mistura à água que brilha sobre a pele, o vento e o som da canção ninam uma criança na rede que balança. Um mundo em circulação e em transformação entre gentes e materiais: rio, chão, vegetais, água, fogo, vento, mães, crianças, avós, irmãs, irmãos... Tudo está em movimento, a vida é movimento. "O ritmo da aldeia é assim, é o ritmo do Yudjá. Ninguém fica parado. Só fica parado quando está doente. Agora quando está bem de saúde é todo dia.”. São as palavras de Yabaiwá que fecham esta sequência de imagens. Para Ingold (2017), bastante ligado aos conceitos de linhas de fuga de Gilles Deleuze e Felix Guattari e da Evolução criadora, de Henri Bergson (apud INGOLD, 2017), a ideia de que vida está nos movimentos relacionais e nos processos e não em unidades essenciais contida nos seres:

Diz Bergson, estamos inclinados a tratar o ser vivo que entrou em uma espiral em si mesmo como um objeto delimitado externamente, ou como um recipiente para a vida. No entanto, Bergson insistiu que a vida não está contida nas coisas. É do próprio movimento no qual cada organismo emerge como perturbação peculiar, que irrompe um fluxo linear (INGOLD, 2017, p. 3940).

Nessa perspectiva, vida é movimento, desestabilização e criação constante entre materiais e seres diferentes, a vida se dá nas trajetórias em devir. Para o autor, não é possível alcançar os fins da vida, pode-se apenas pensar em linhas de vida que se dão entre seres e materiais. A vida é o fluxo, a água que flui e não as margens que fixam. (INGOLD, 2017, p. 41). A organização disciplinar do pensamento moderno fixase nas margens, separa os humanos do mundo dos materiais: as Ciên- 
cias Humanas em uma margem e as ciências da natureza em outra, e separadas pouco se lançam a pensar nos fluxos que se dão no entre.

Figura 3 frame 05:54 do filme Waapa

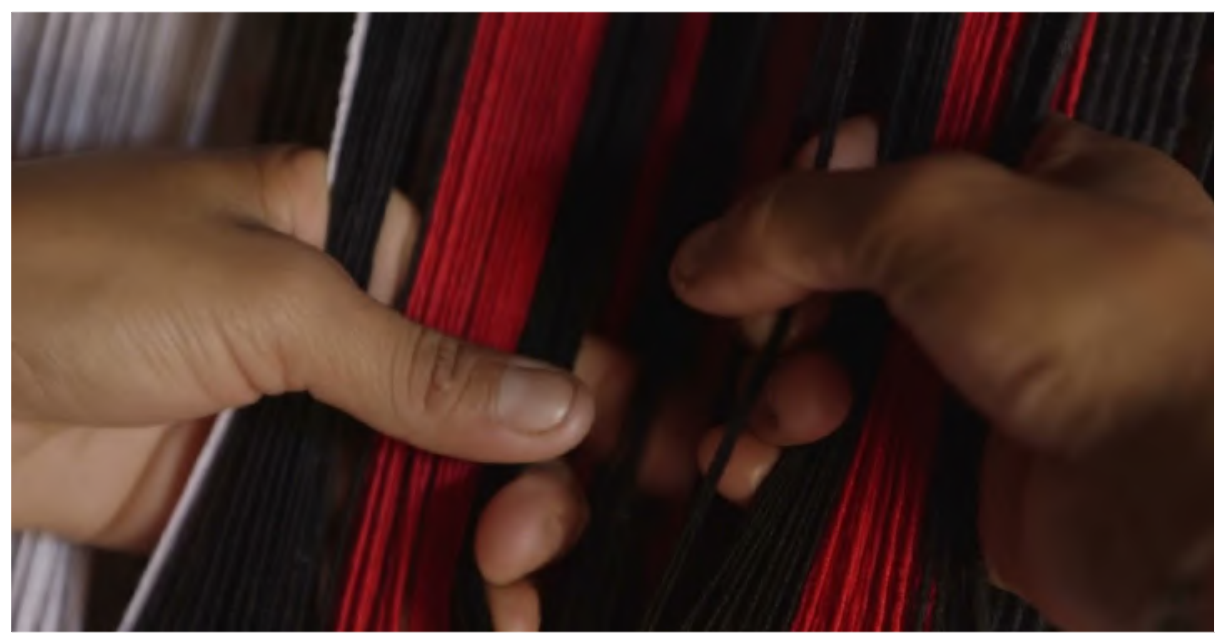

Figura 4 frame 05:58 do filme Waapa

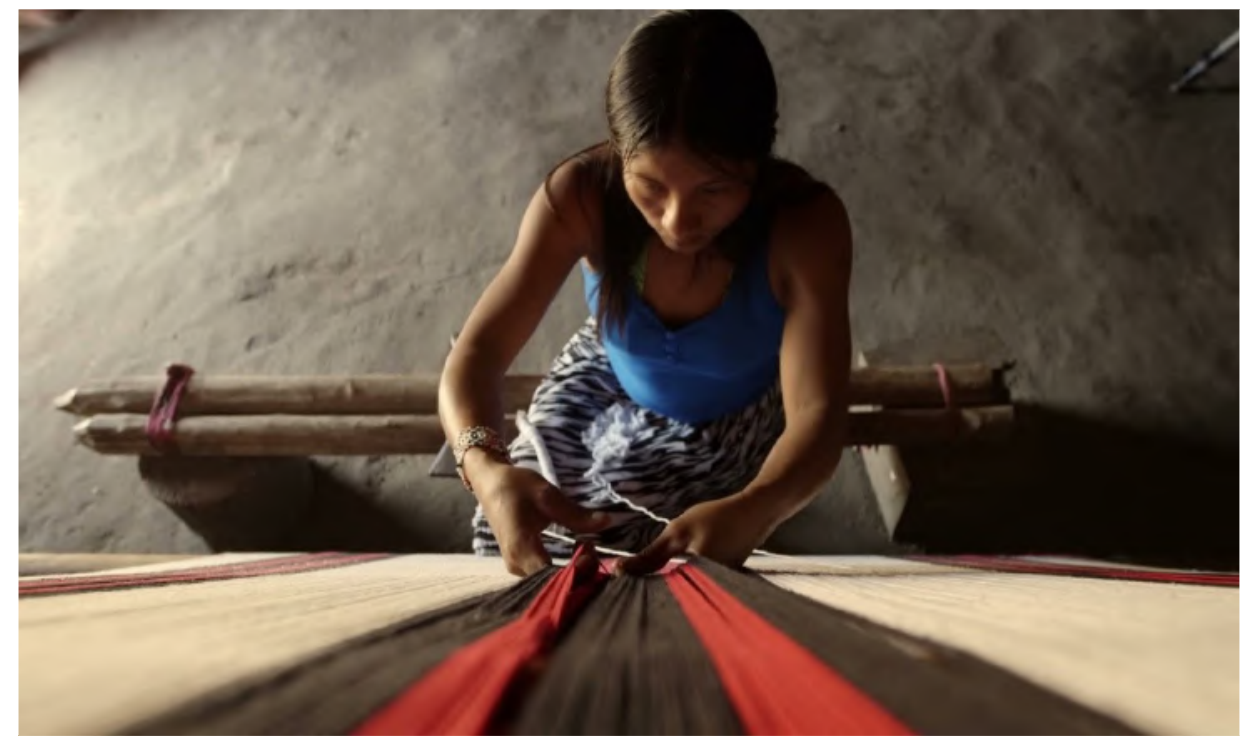


Figura 5 frame 04:00 do filme Waapa

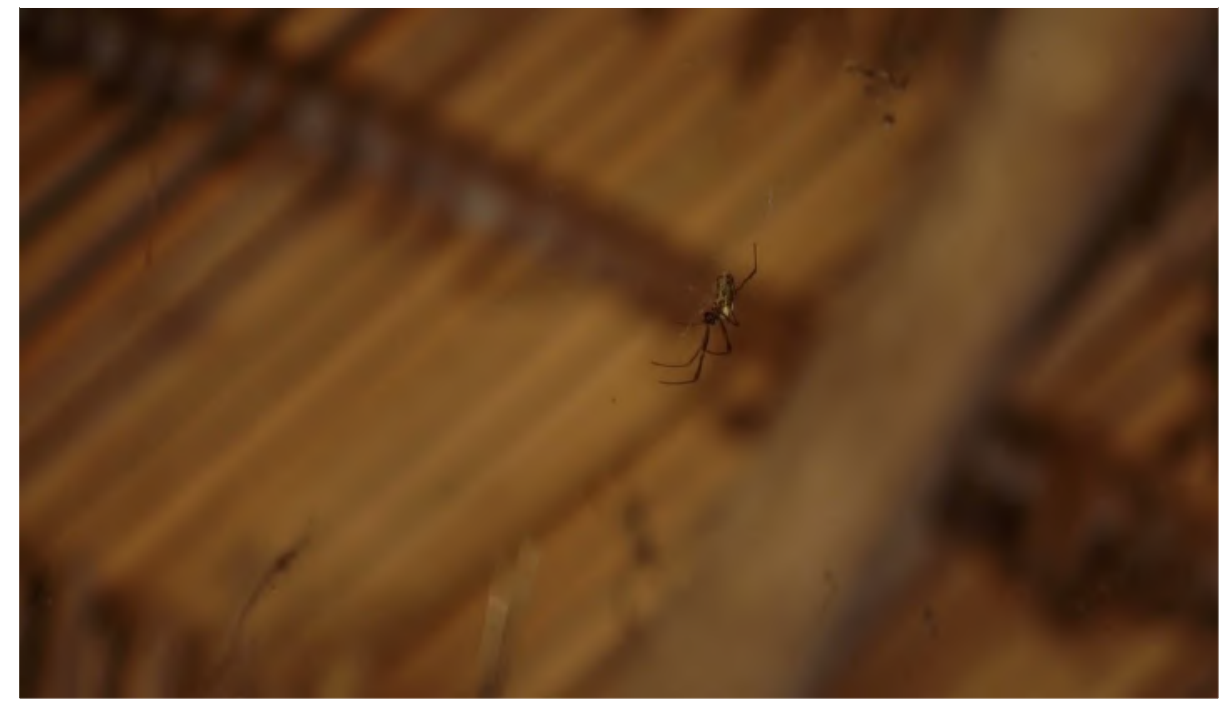

Figura 6 frame 06:11 do filme Waapa

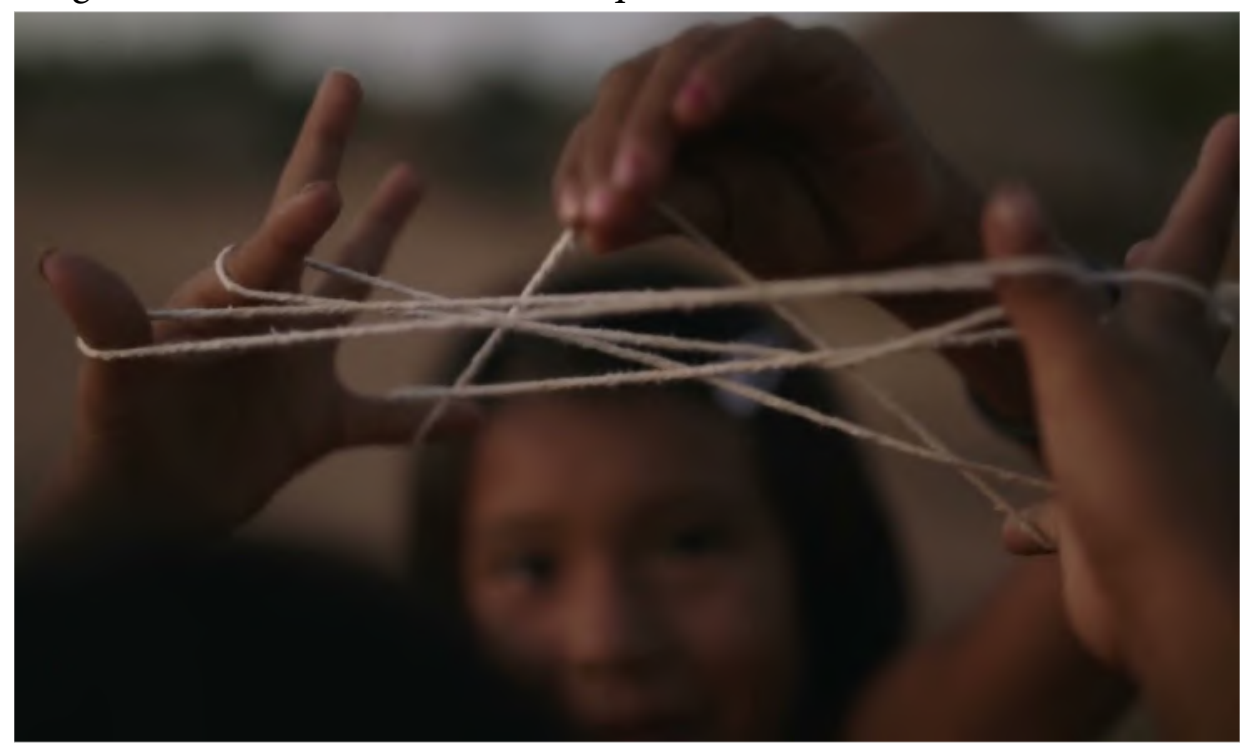


"Essa aranha, que os povos usam há muito tempo, morava com deus. Ela confeccionava todos os tecidos de algodão como rede e cobertor. Dizem que ela tecia dia inteiro. E deus disse para uma visitante: essa é minha tecelã”. Narra uma mulher yudjá enquanto passa suavemente a aranha nas mãos de uma menina. Depois, também suavemente, deixa que a aranha pique as pontas do dedo da tecelã aprendiz. Nas palavras de Yabaiwá, o veneno da aranha é o remédio que prepara o corpo, é aquilo que traz o conhecimento e a habilidade. E enquanto a criança recebe o remédio, a mulher realiza uma cúmplice conversação com as aranhas: "Passe sua arte de tecer, que seja uma boa tecelã. Passe sua arte de tecer para ela, aranha. Que ela consiga fazer uma rede". As palavras da tecelã adulta parecem fazer parte do agenciamento das forças. Nesta perspectiva, a aranha é um ser que sabe e que ensina, e as mulheres precisam pedir para que a sabedoria seja entregue do mundo aracnídeo ao mundo humano. Elas não estão na posição de quem sabe sobre as aranhas e as utilizam como um recurso, um simples princípio ativo; diferente disso solicitam a ajuda às aranhas, colocam-se no lugar de quem aprende com e tece junto. Há uma teia comum sendo continuamente tecida entre as mulheres, as aranhas e a aranha de deus. A picada e as palavras fazem o vínculo, o veneno é remédio, as palavras abrem a subjetividade a uma aliança entre mundos.

O filme recebe um fio e se lança nessa fiação comum. Tece poeticamente sons, imagens e palavras: as mãos deslizam pelos fios dos teares yudjá, entram no mesmo ritmo leve das aranhas que lançam seus fios na vida cotidiana da aldeia e a aldeia amplia suas teias. As cenas do filme são alinhadas pelo som das flautas que dão continuidade aos ritmos das meninas-aranhas e das aranhas-meninas, que criam um mundo todo emaranhado por fios invisíveis.

"Saracura corre com ele, vai", diz um homem yudjá, enquanto arranha as pernas de um menino com as garras da ave corredora. "Não vão te derrubar, vai te deixar firme" diz enquanto passa nas pernas de uma criança as fibras uma árvore molhadas com a águas do rio. Depois, joga com força as fibras no rio. "Rio leva a fraqueza em- 
bora”. A árvore, a ave, o rio, as palavras e o corpo da criança formam linhas de velocidade, força e equilíbrio. Nas brincadeiras de preparo do corpo, os remédios são os materiais das plantas, dos animais e as águas do rio e, adensadas aos materiais, estão as forças espirituais que Yabaiwá chama de "donos dos remédios". As garras da saracura ensinam a agilidade, o veneno da aranha e o algodão queimado ensinam a habilidade de tecer, a ponta da castanha queimada e o sumo de uma folha ensinam a pontaria, o tronco de uma árvore ensina o equilíbrio.

"Lua olha para ele, atende o pedido dele", diz um homem yudjá enquanto espreme o sumo de uma folha nos olhos do menino, preparando-o para ser um bom atirador de flecha. Os seres celestiais também interferem e fazem parte dos processos educativos yudjá. A lua nova potencializa a abertura do corpo para a recepção dos ensinamentos, é uma importante linha na malha de relações dos yudjá e marcadora do tempo propício para as brincadeiras. Os narradores inserem a lua na malha complexa de aprendizagem entre gentes, plantas, animais e o rio. "A lua, quando nasce, é bem baixinha ainda, é frágil. Ela é mole e quando você está pedindo para a lua, seu corpo também fica mole e ele recebe muito rápido a essência do remédio, a força do remédio. Quando a lua está quase cheia já passou o momento de passar os remédios, mas quando ela está bem fininha, ela está nova ainda. Nesta fase ela ainda é frágil e nós aproveitamos para usar os remédios. Então pedimos para a lua olhar e passar os ensinamentos para quem está usando os remédios. Passar o ensinamento para aquela criança.” A lua não é apenas vista, a lua olha. A lua não é um objeto de conhecimento, é uma subjetividade que ensina. Para os yudjá, a lua educa e seus corpos se abrem a cada novo ciclo lunar. $\mathrm{O}$ filme nesse momento faz as mãos, o barro e a lua misturarem-se na imagem. O corpo e o barro amolecem para receber o remédio na lua nova, o filme também fica mole.

O barro vira lua, as mãos e o barro fazem um fio de lua nascer. 


\section{Figura 7 frame 06:42 do filme Waapa}

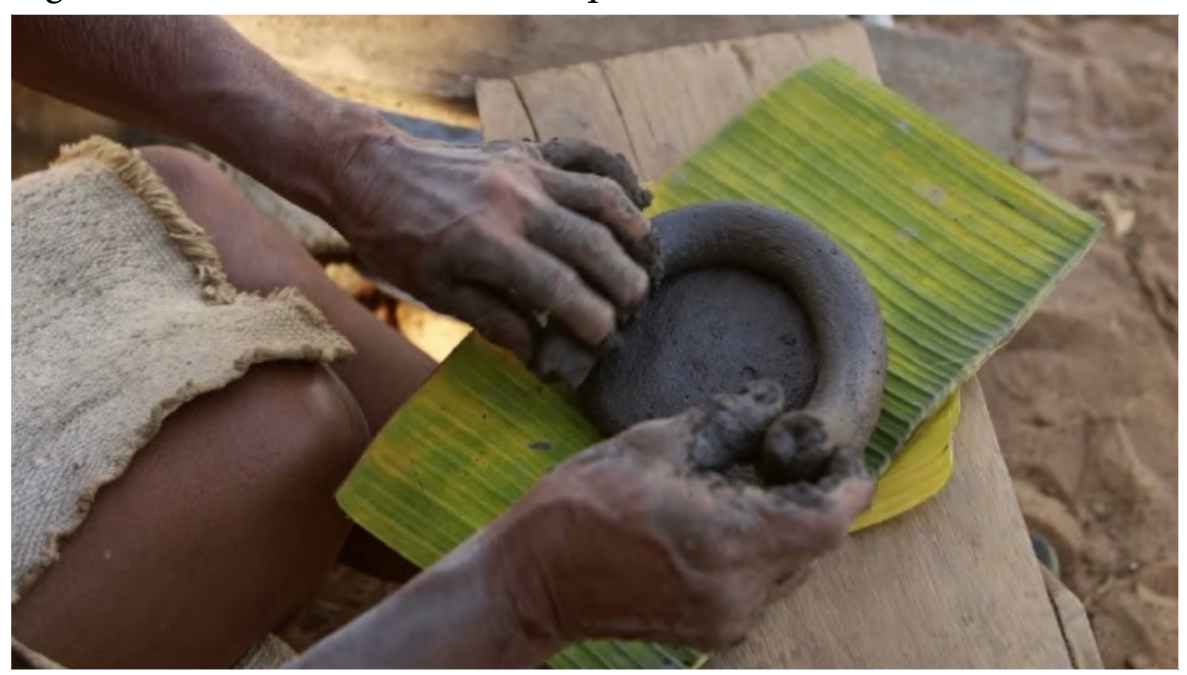

Figura 8 frame 06:55 do filme Waapa

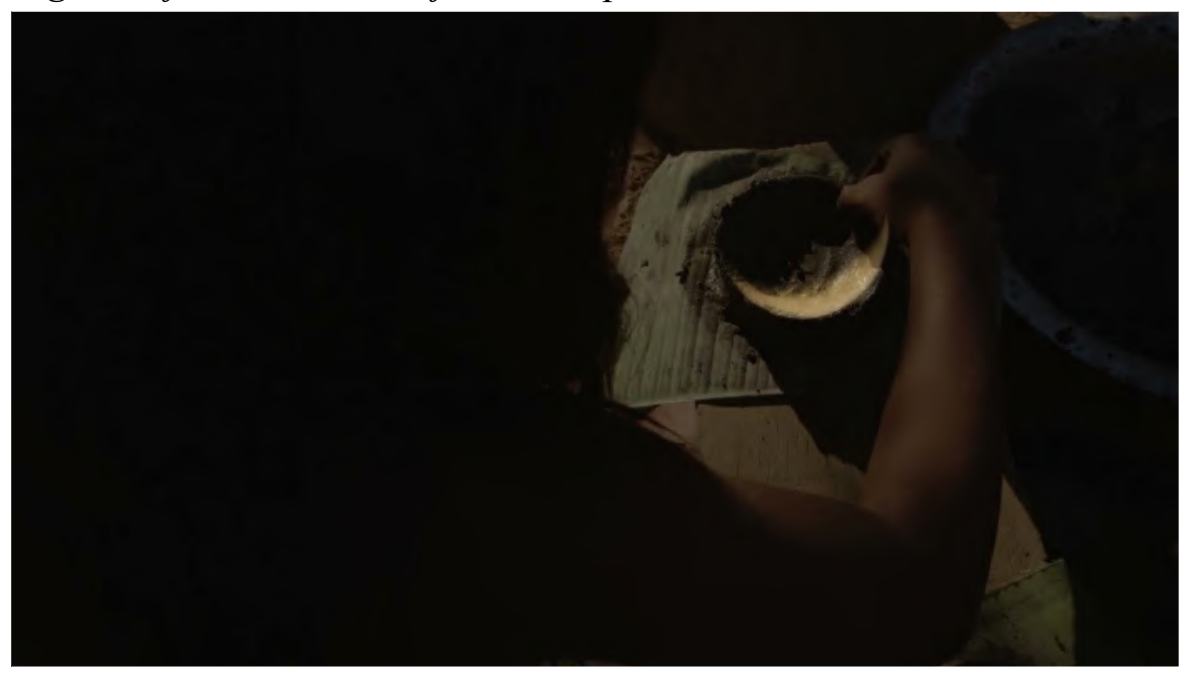


Figura 9 frame 07:00 do filme Waapa

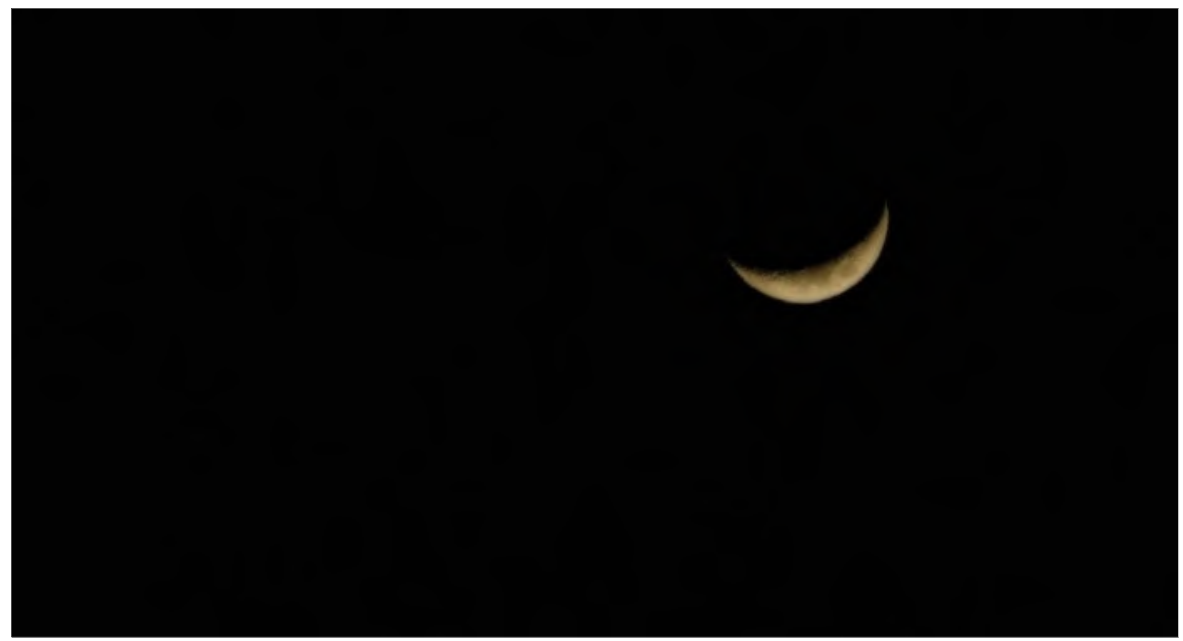

Os Yudjá fazem essa circulação humana no espaço, numa metafísica da mistura com os cosmos. O remédio não é apenas uma substância, que atua sobre um corpo material. A conversa com os seres e a brincadeira fortalecem o vínculo e as conversações, potencializam os devires: gente-pássaro, gente-rio, gente-árvore, gente-aranha... O mundo yudjá não é apenas aquele desenhado pela perspectiva humana, há muitas perspectivas convivendo em relação, não há essencialidade, há sempre relações entre diferentes subjetividades. As subjetividades humanas parecem ser mais permeáveis às forças não humanas.

Olhando para a educação yudjá a partir da provocação teórica de Tim Ingold, pode-se pensar nessas brincadeiras como uma forma de colocar as crianças em fluxo com os materiais do mundo. Neles, as coisas/seres ensinam em uma relação de contato e mistura com o corpo da criança e também por meio de uma conversação cósmica sempre aberta. Ingold discorda das teorias antropológicas convencionais, que compreendem o animismo de alguns povos indígenas como um "sistema de crenças que atribui vida ou espírito a coisas que são verdadeiramente inertes". Defende uma outra perspectiva de pensamento:

Em primeiro lugar, estamos lidando aqui não com um maneira de acreditar sobre o mundo, mas com uma condição de estar 
nele. Isto poderia ser descrito como uma condição de estar vivo para o mundo, caracterizada por uma maior sensibilidade e capacidade de resposta, na percepção e na ação, a um ambiente que está sempre em fluxo, nunca o mesmo de um momento para o outro. A animacidade, portanto, não é uma propriedade das pessoas imaginariamente projetada sobre as coisas pelas quais se percebem cercadas. Em vez disso - este é o meu segundo ponto - trata-se do potencial dinâmico, transformador de todo o campo de relações dentro do qual seres de todos os tipos, mais ou menos semelhantes a pessoa ou a coisas, continuam e reciprocamente trazem uns aos outros à existência (INGOLD, 2017, p. 116).

A educação yudjá coloca as crianças nessa condição de estarem "vivas para um mundo" em constante fluxo, coloca-as na experiência de, em seus corpos, darem existência a outros seres. $\mathrm{O}$ conhecimento se faz a partir de misturas, vínculos, conversas e alianças afetivas com o rio, os pássaros, as sementes, as árvores, as aranhas, o fogo, a fumaça, a lua...

O grande e caudaloso Rio Xingu retorna junto com as palavras sábias do narrador. "E assim nós estamos circulando também, essa é a nossa circulação no espaço. E assim que você consegue se relacionar com esse mundo maior. É assim que você abre mais visão, é uma forma de você lidar com ele. Você respeita e também vai ser respeitado porque você é uma pessoa que está comunicando. Você está trazendo uma mensagem e também está transmitindo a mensagem. Da terra para o mundo e você recebe esta mensagem do mundo para o ser humano".

Como inserir as coisas e os seres não humanos nas nossas práticas e teorias educacionais? Como potencializar a educação, compreendendo-a como um gesto ampliado para além das trocas entre humanas/os? O que as coisas/seres com os quais convivemos nos educam? Damos tempo e espaço para que crianças entrem em conversações e aprendizagens com as coisas/seres? Como potencializar processos em que os seres/coisas possam ensinar? Que subjetividades estamos crian- 
do nas nossas formas de educar confinadas em espaços fechados? Estas perguntas desejam ampliar nossos horizontes existenciais de modo a enriquecer nossas subjetividades com imagens de outras humanidades que coabitam um mundo repleto de perspectivas não humanas. Krenak, a respeito de sua trajetória de vida entre mundos indígenas e não indígenas diz: "O desafio que eu tive que encarar foi o de admitir a existência de inumeráveis mundos que circundam, que se articulam e que se comunicam com o mundo em que eu transito." Ele convida a esse desafio de ampliar os horizontes imaginando mundos em possível coexistência, mundos que se criam nos diversos modos humanos e não humanos de habitar o planeta. Ele convida a resistir à ideia homogeneizadora e autoritária de um mundo único, criando outras formas de aliança:

As possibilidades de aliança não se dão só no plano das relações sociopolíticas, no plano das ideias, no que é possível estabelecer de colaboração entre uma nação e outra, entre uma sociedade e outra. Quando eu vou a um riacho, a uma fonte, a uma nascente e sinto beleza e fico comovido com a água que está naquela fonte, naquela nascente, eu estabeleço uma relação com ela, converso com ela, eu me lavo nela, bebo aquela água e crio uma comunicação com aquela entidade água que, para mim, é uma dádiva maravilhosa, que me conecta com outras possibilidades de relação com as pedras, com as montanhas, com as florestas. As relações não são percebidas como potência que ocorre só entre pessoas, no sentido comum em que nós entendemos as pessoas, as relações humanas, as relações sociais. Elas são alianças com muitas outras potências que estão dadas, que são possíveis. $\mathrm{O}$ raio, a chuva, o vento, o sol, a brisa, as paisagens. Aliança é troca com todas as possibilidades, sem nenhuma limitação (KRENAK , 2016, s/p).

Os Yudjá seguem, na vida e no filme, em sua cúmplice e ilimitada aliança com o rio. O Xingu faz os meninos desaparecerem em sua névoa. As crianças remam a canoa, em que um velho segue tocando 
uma flauta. De novo, como no início do filme, não se sabe para onde vão. Yabaiwá presenteia em suas últimas palavras com uma imagem que dá pistas sobre a direção dessa canoa yudjá. "O rio também se comunica com a gente. Onde a gente nasceu a gente circulou tudo e hoje a gente está voltando para encontrar com a ponta. Por isso que a gente fala que hoje a gente está quase chegando no passado, mas até fazer esse círculo a gente tem que estar bem emendado com o começo. Se a gente cuidar bem do mundo, nossa vida vai ser infinita, a gente vai ficar para sempre”.

\section{Referências}

FARGETTI, Cristina Martins. Fala de bicho, fala de gente: cantigas de ninar do Povo Juruna. Participação de Marlui Miranda, São Paulo: Edições SESC, 2017.

INGOLG, Tim. Estar vivo: ensaios sobre movimento, conhecimento e descrição. São Paulo: Editora Vozes, 2017.

JOSHUA, Hirondina. Os ângulos da casa. Maputo, Moçambique: Fundação Fernando Couto, 2016.

KRENAK, Ailton. As Alianças Afetivas. As alianças afetivas. Entrevista com Ailton Krenak por Pedro Cesarino, 2016. Disponível em: $<$ https://www.academia.edu/37323976/As alian\%C3\%A7as afetivas _entrevista com Ailton Krenak por Pedro Cesarino $>$ Acesso em: 15 jan. 2020.

. Ideias para adiar o fim do mundo. São Paulo: Companhia das Letras, 2019.

LANA, Luiz \& LANA, Firmino. Antes o mundo não existia: mitologia dos antigos Desana-Kehípõrã. São João Batista do Tiquié: UNIRT; São Gabriel da Cachoeira: FOIRN, 1995.

MEIRELLES, Renata, REEKS David; MENDONÇA, Paula. Waapa. Curta Metragem (20min), São Paulo: Maria Farinha Produções, 2017 Disponível em: <https://www.videocamp.com/en/movies/waapa $>$ Acesso em: 15 jan. 2020. 
MENDONÇA, Paula. Corpo preparado, alma protegida: jeitos de cuidas e modos de aprender no crescimento da criança yudjá. Dissertação (Mestrado em Educação), Faculdade de Educação, Universidade Estadual de São Paulo, 2017.

MIRANDA, Marlui. CD- Fala de bicho, fala de gente. São Paulo: Selo SESC, 2014.

VIVEIROS DE CASTRO, Eduardo \& SZTUTMAN, Renato. Encontros. Eduardo Viveiros de Castro. Organização. Rio de Janeiro: Beco do Azougue, 2008.

WUNDER, Alik. Encontros com poéticas indígenas, férteis fronteiras entre a educação e as artes. Revista Questio, v. 19 n. 3, 2017. 
